\title{
Unique two-dimensional indium telluride templated by a rare wheel-shaped heterobimetallic Mn/In cluster
}

Yao Fu, ${ }^{+, *}$ Jian Zhou, ${ }^{,+,+*}$ Hua-Hong Zou, ${ }^{*, \neq}$ Filipe A. Almeida Paz, ${ }^{\S}$ Xing Liu, ${ }^{\dagger}$ and Lianshe

$$
\mathrm{Fu}^{\mathbb{s}, \$}
$$

${ }^{\dagger}$ Chongqing Key Laboratory of Inorganic Functional Materials, College of Chemistry, Chongqing Normal University, Chongqing 401331, P. R. China

${ }^{\star}$ State Key Laboratory for Chemistry and Molecular Engineering of Medicinal Resources, School of Chemistry \& Pharmacy of Guangxi Normal University, Guilin 541004, P. R. China

${ }^{\S}$ Department of Chemistry, CICECO - Aveiro Institute of Materials, University of Aveiro, Campus Universitário de Santiago, 3810-193 Aveiro, Portugal.

,SPhantom-g, CICECO - Aveiro Institute of Materials, Department of Physics, University of Aveiro, 3810-193 Aveiro, Portugal 
General Remarks. All analytical grade chemicals were obtained commercially and used without further purification. Elemental analyses $(\mathrm{C}, \mathrm{N}$ and $\mathrm{H})$ were performed using a PE2400 II elemental analyzer. IR spectra were obtained from a powdered sample pelletized with $\mathrm{KBr}$ on an ABB Bomen MB 102 series IR spectrophotometer in the range of $400-4000 \mathrm{~cm}^{-1}$. Energy-dispersive X-ray analysis (EDXA) was taken by using a JEOL JSM-6700F field-emission scanning electron microscope. Room-temperature optical diffuse reflectance spectra of the powdered samples were obtained with a Shimadzu UV-3150 spectrometer. The absorption $(\alpha / \mathrm{S})$ data were calculated from the reflectance using the Kubelka-Munk function, $\alpha / \mathrm{S}=(1$ - $\mathrm{R})^{2} / 2 \mathrm{R}$, where $\mathrm{R}$ is the reflection coefficient, $\alpha$ is the absorption coefficient, and $\mathrm{S}$ is the scattering coefficient. PXRD patterns were obtained using a Bruker D8 Advance XRD diffractometer with $\mathrm{Cu} \mathrm{K} \alpha$ radiation $(\lambda=1.54178 \AA)$. The magnetization of 1 was obtained with a Quantum Design MPMS-XL-5 magnetometer. PXRD patterns were obtained using a Bruker D8 Advance XRD diffractometer with $\mathrm{Cu} \mathrm{K} \alpha$ radiation $(\lambda=1.54056 \AA)$. The working electrodes for photocurrent measurements were prepared by following processes. $8 \mathrm{mg}$ of microcrystal sample was dispersed into a mixed solution of ethanol $(200 \mu \mathrm{L})$ and Nafion $(56 \mu \mathrm{L})$, followed by ultrasonic treatment for $0.5 \mathrm{~h}$. Then, $210 \mu \mathrm{L}$ of the above slurry was coated onto the FTO glass (F-doped $\mathrm{SnO}_{2}$ ) with an effective area of $1 \mathrm{~cm}^{2}$ and dried naturally at room temperature. The photocurrent experiment was performed on a CHI650E electrochemistry workstation in a three-electrode system, with the sample coated FTO glass as the working electrode, a Pt slice as the auxiliary electrode and a saturated calomel electrode (SCE) as the reference electrode. The supporting electrolyte solution was $0.1 \mathrm{~mol} \cdot \mathrm{L}^{-1} \mathrm{Na}_{2} \mathrm{SO}_{4}$ aqueous solution $(100 \mathrm{~mL})$. A $450 \mathrm{~W}$ high pressure Xe lamp with $420 \mathrm{~nm}$ was used as the illumination source. The lamp was kept on continuously, and a manual shutter was used to block exposure of the sample to the light. The sample was typically irradiated at intervals of $100 \mathrm{~s}$.

\section{Crystal Structure Determination}


The intensity data of $\left[\mathrm{Mn}_{4.78} \operatorname{In}_{2.22}(\mathrm{ea})_{12}\right]_{n}\left[\operatorname{In}_{9.79} \mathrm{Mn}_{0.21} \mathrm{Te}_{17}\right]_{\mathrm{n}}$ were collected on a Bruker diffractometer-SMART-APEX II with graphite monochrochromated Mo Ka radiation $(\lambda=0.71073 \AA)$. Data reduction and absorption corrections were performed using the SAINT and SADABS software packages, respectively. The structure of $\left[\mathrm{Mn}_{4.78} \operatorname{In}_{2.22}(\mathrm{ea})_{12}\right]_{\mathrm{n}}\left[\operatorname{In}_{9.79} \mathrm{Mn}_{0.21} \mathrm{Te}_{17}\right]_{\mathrm{n}}$ was solved by direct methods and refined by full-matrix least-squares methods on $F^{2}$ using the SHELXL-2018 program package.The refinement with three octahedral metal sites occupied by three $\mathrm{Mn}^{2+}$ ions and one tetrahedral metal site occupied by one $\mathrm{In}^{3+}$ ion results in a molecular formula of $\left[\mathrm{Mn}_{7}(\mathrm{ea})_{12}\right]_{n}\left[\operatorname{In}_{10} \mathrm{Te}_{17}\right]$. The stoichiometry of $\left[\mathrm{Mn}_{7}(\mathrm{ea})_{12}\right]_{\mathrm{n}}\left[\operatorname{In}_{10} \mathrm{Te}_{17}\right]$ creates a charge of -2 , which is not obviously rational. The U(iso) values of Mn2-4 are obviously smaller and the U(iso) value of In2 is obviously larger. When three octahedral metal sites are occupied by In6/Mn2, In7/Mn3 and In8/Mn4 atoms with occupation factors of $0.308 / 0.692,0.334 / 0.666$ and $0.469 / 0.531$, respectively, and one tetrahedral metal site is occupied by $\operatorname{In} 2 / \mathrm{Mn} 5$ atom with occupation factor of $0.893 / 0.107$, the final $R$ and $w R$ factors $(I>2 \sigma(I))$ are decreased from $0.0643 / 0.2225$ to $0.0373 / 0.0973$. So its formula was finally determined as $\left[\mathrm{Mn}_{4.78} \operatorname{In}_{2.22}(\mathrm{ea})_{12}\right]_{\mathrm{n}}\left[\operatorname{In}_{9.79} \mathrm{Mn}_{0.21} \mathrm{Te}_{17}\right]_{\mathrm{n}}$. The Te5, C6 and C8 atoms were disordered over site occupation factors of $0.89 / 0.11,0.52 / 0.48$ and 0.34/0.66, respectively. The non-hydrogen atoms were refined anisotropically. $\mathrm{H}$ atoms were placed in idealized locations and refined as riding. Technical details of data collections and refinement are summarized in Table S1.

Table S1 Crystallographic data for $\left[\mathrm{Mn}_{4.78} \operatorname{In}_{2.22}(\mathrm{ea})_{12}\right]_{\mathrm{n}}\left[\operatorname{In}_{9.79} \mathrm{Mn}_{0.21} \mathrm{Te}_{17}\right]_{\mathrm{n}}$.

\begin{tabular}{ll}
\hline formula & $\mathrm{C}_{24} \mathrm{H}_{72} \mathrm{In}_{12} \mathrm{Mn}_{5} \mathrm{~N}_{12} \mathrm{O}_{12} \mathrm{Te}_{17}$ \\
$F w$ & 4543.11 \\
crystal system & Monoclinic \\
space group & $C 2 / \mathrm{c}$ \\
$a, \AA$ & $25.7155(14)$ \\
$b, \AA$ & $13.4091(7)$ \\
\hline
\end{tabular}




\begin{tabular}{ll}
\hline$c, \AA$ & $25.7626(15)$ \\
$\beta$, deg & $101.825(2)$ \\
$V, \AA^{3}$ & $8695.0(8)$ \\
$Z$ & 4 \\
$T, \mathrm{~K}$ & $296(2)$ \\
Calcd density,Mg.m ${ }^{-3}$ & 3.470 \\
abs coeff, mm ${ }^{-1}$ & 9.446 \\
$F(000)$ & 7972 \\
$2 \theta($ max $)$, deg & 55.76 \\
Total reflns collected & 31960 \\
Unique reflns & 10221 \\
No. of param & 399 \\
$R 1[I>2 \sigma(I)]$ & 0.0373 \\
$w R 2($ all data $)$ & 0.0973 \\
GOF on $F^{2}$ & 1.071 \\
\hline
\end{tabular}

Table S2 The selected In-Te, In-O/N, Mn-Te and Mn-O/N bond lengths of $\left[\mathrm{Mn}_{4.78} \operatorname{In}_{2.22}(\mathrm{ea})_{12}\right]_{\mathrm{n}}\left[\operatorname{In}_{9.79} \mathrm{Mn}_{0.21} \mathrm{Te}_{17}\right]_{\mathrm{n}}$.

\begin{tabular}{llll}
\hline In-Te & $2.6953(9)-2.9148(8)$ & In-O & $2.07(3)-2.29(3)$ \\
In-N & $2.26(3)-2.39(2)$ & Mn-O & $2.09(3)-2.36(2)$ \\
Mn-N & $2.14(3)-2.36(3)$ & Mn-Te & $2.683(13)-2.855(11)$ \\
\hline
\end{tabular}


Te $L \alpha 1$

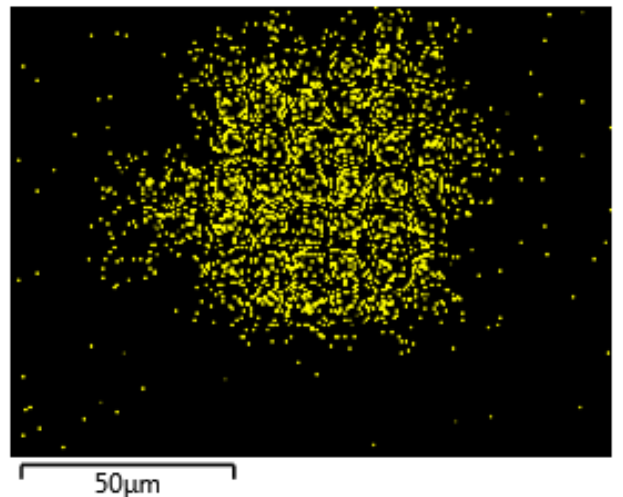

$50 \mu \mathrm{m}$

In $L \alpha 1$

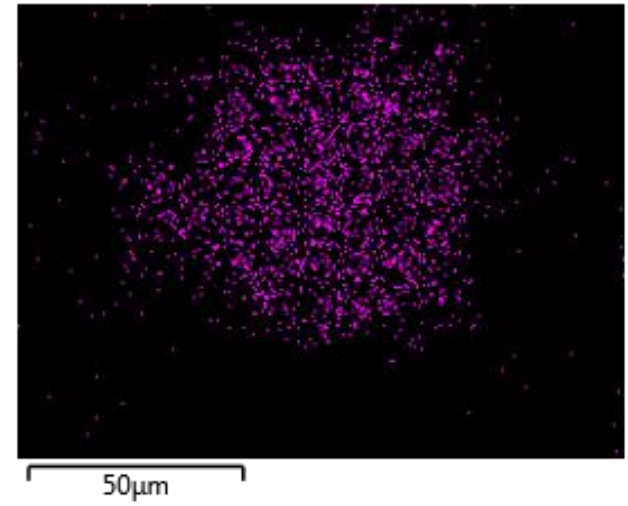

Mn K $\alpha 1$

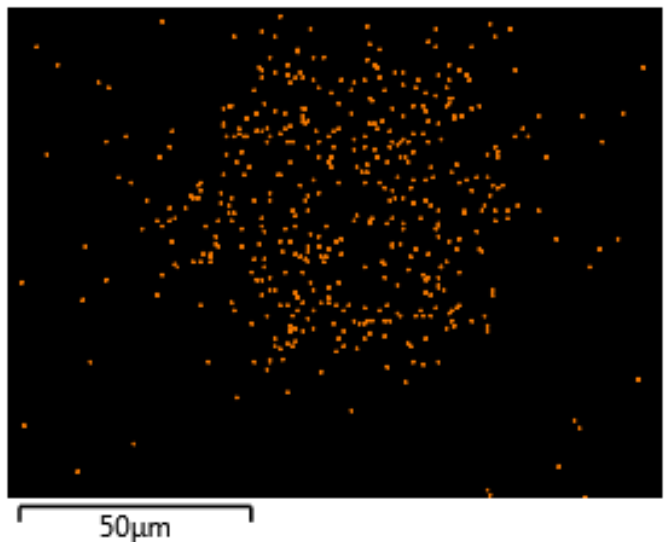

$50 \mu \mathrm{m}$

Figure S1 EDXA elemental mappings of Te, In and Mn in

$\left[\mathrm{Mn}_{4.78} \operatorname{In}_{2.22}(\mathrm{ea})_{12}\right]_{\mathrm{n}}\left[\operatorname{In}_{9.79} \mathrm{Mn}_{0.21} \mathrm{Te}_{17}\right]_{\mathrm{n}}$.

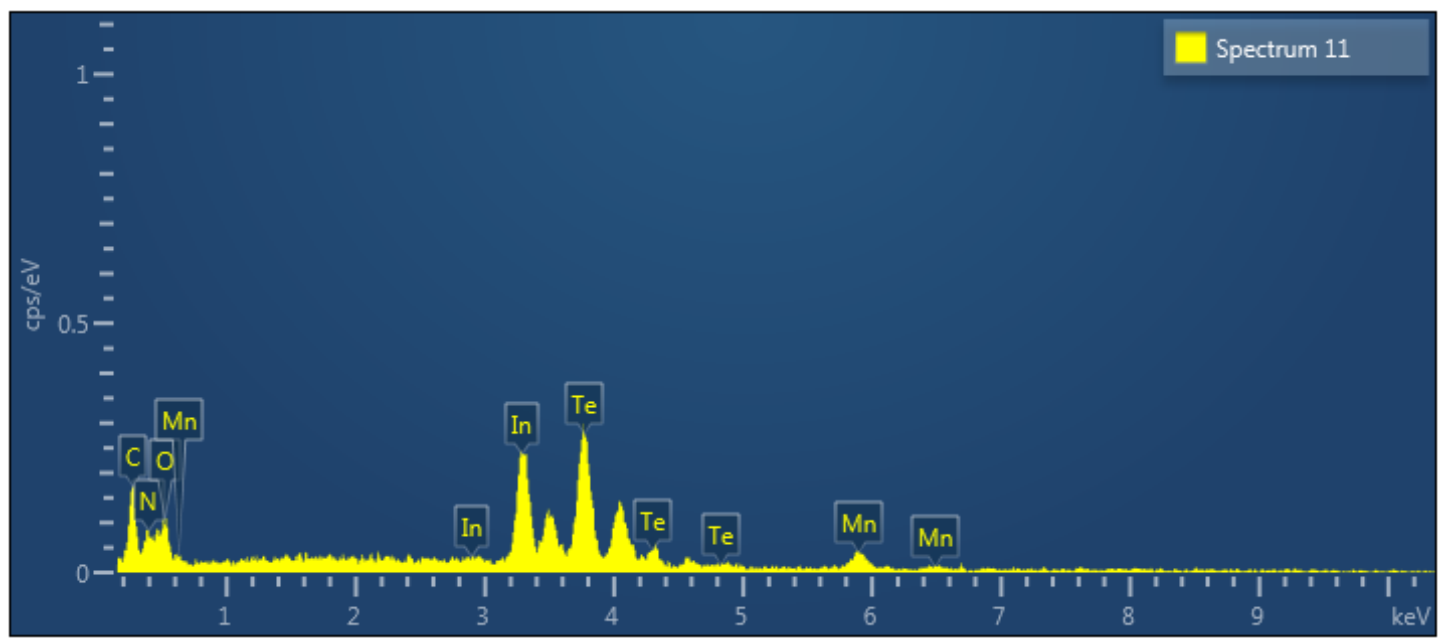

Figure S2 EDXA spectrum of $\left[\mathrm{Mn}_{4.78} \operatorname{In}_{2.22}(\mathrm{ea})_{12}\right]_{\mathrm{n}}\left[\operatorname{In}_{9.79} \mathrm{Mn}_{0.21} \mathrm{Te}_{17}\right]_{\mathrm{n}}$. 


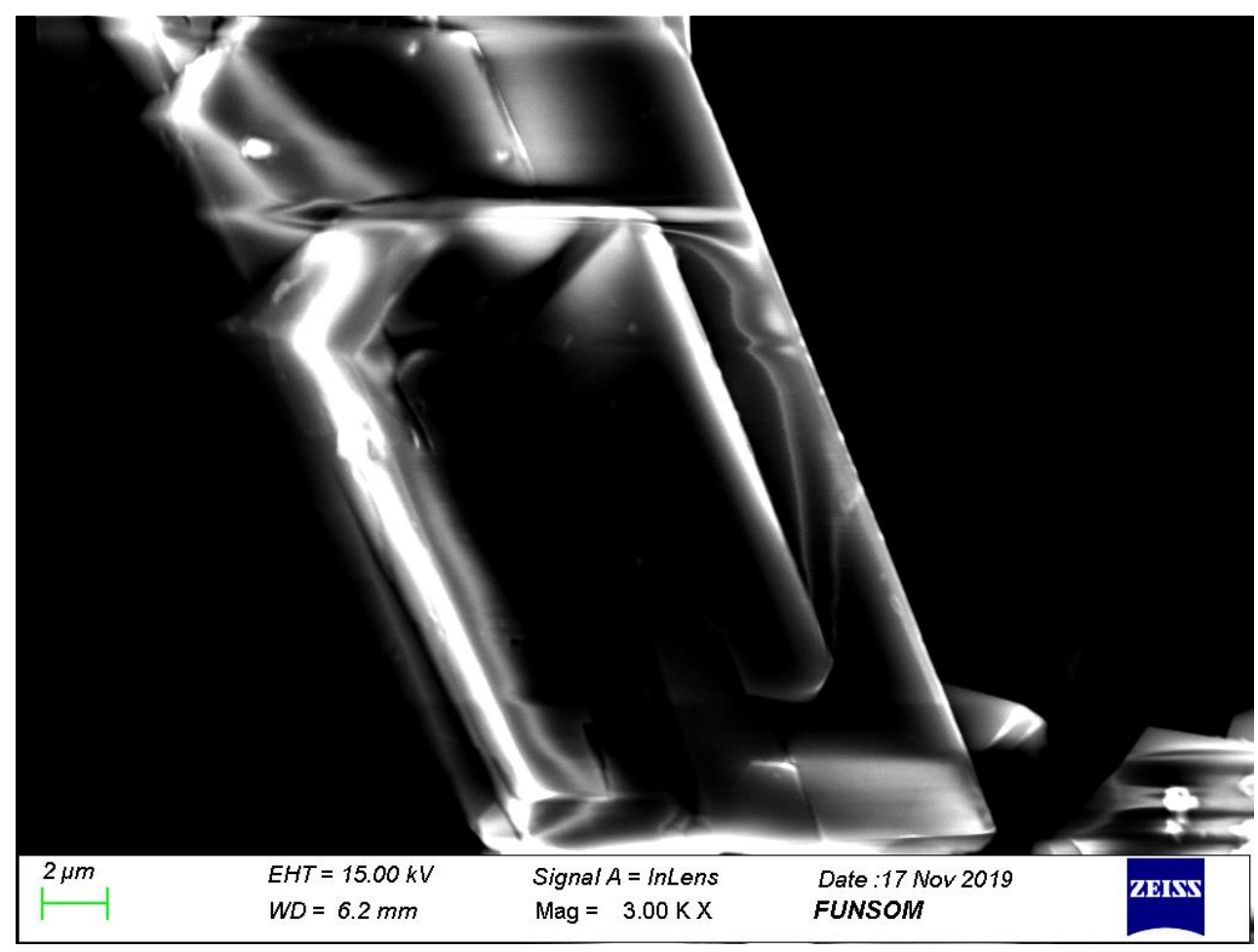

Figure S3 Scanning electron micrograph of $\left[\mathrm{Mn}_{4.78} \operatorname{In}_{2.22}(\mathrm{ea})_{12}\right]_{\mathrm{n}}\left[\operatorname{In}_{9.79} \mathrm{Mn}_{0.21} \mathrm{Te}_{17}\right]_{\mathrm{n}}$.

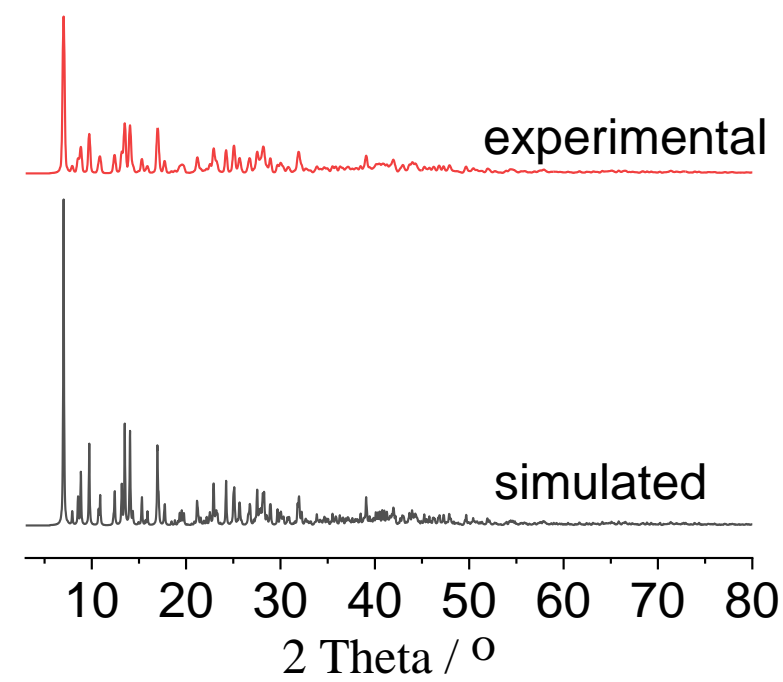

Figure S4 Simulated, and experimental powder XRD patterns of $\left[\mathrm{Mn}_{4.78} \operatorname{In}_{2.22}(\mathrm{ea})_{12}\right]_{\mathrm{n}}\left[\operatorname{In}_{9.79} \mathrm{Mn}_{0.21} \mathrm{Te}_{17}\right]_{\mathrm{n}}$. 


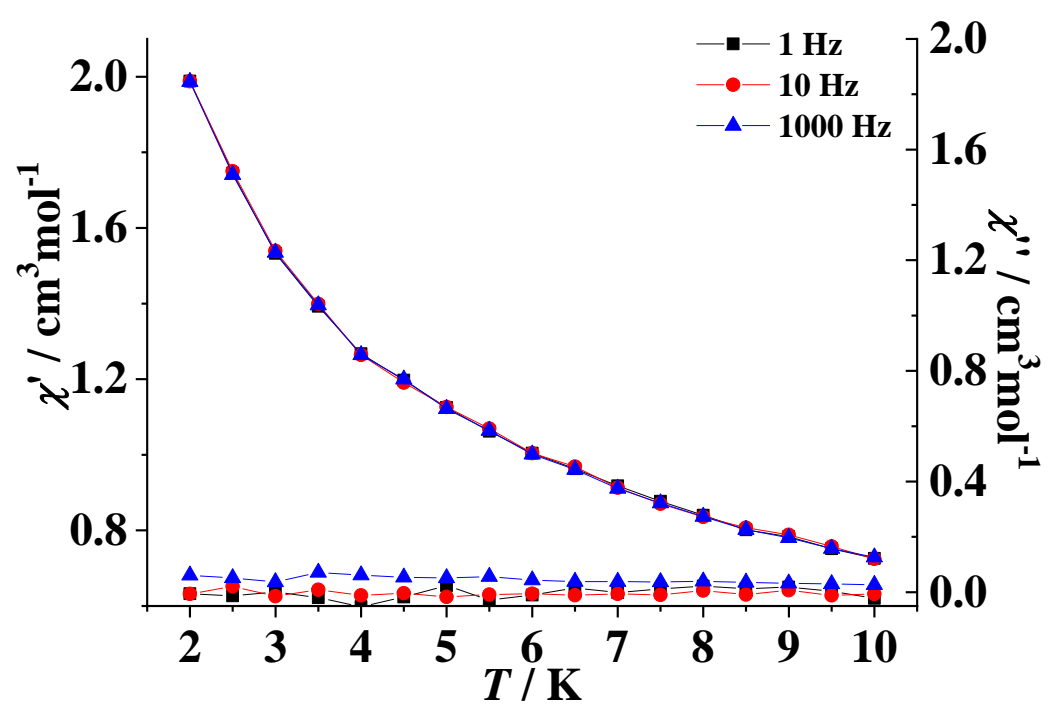

Figure S5 Temperature dependence of the in phase and out-of-phase signals of the ac susceptibility for $\left[\mathrm{Mn}_{4.78} \mathrm{In}_{2.22}(\mathrm{ea})_{12}\right]_{\mathrm{n}}\left[\operatorname{In}_{9.79} \mathrm{Mn}_{0.21} \mathrm{Te}_{17}\right]_{\mathrm{n}}$ under a zero dc field (Hac $=$ $2.5 \mathrm{Oe})$.

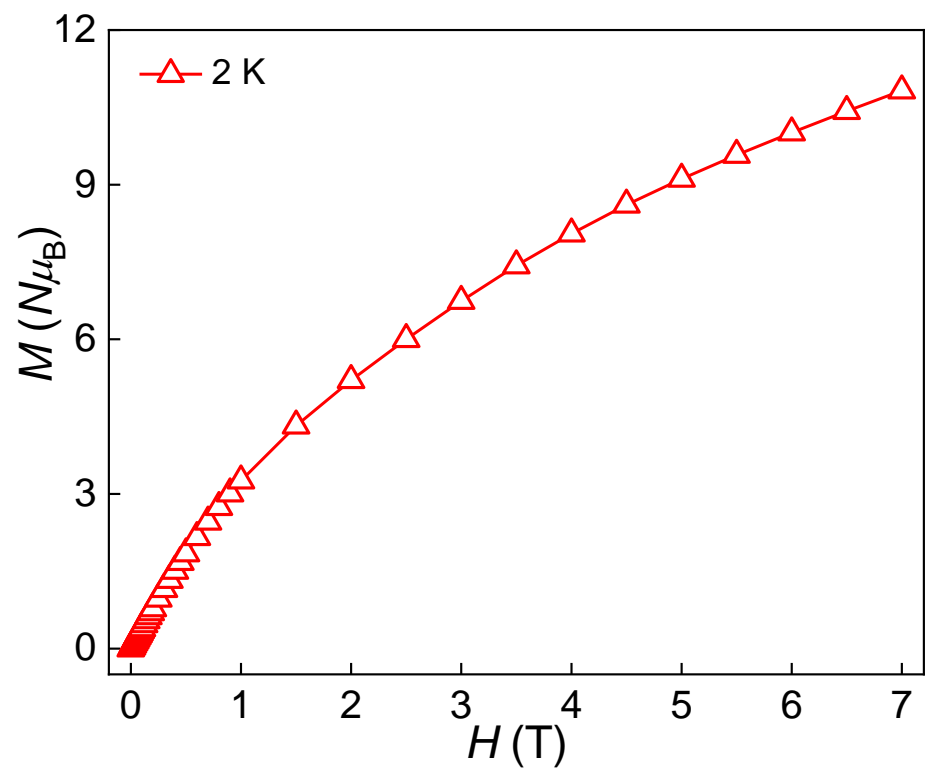

Figure S6 M versus H plot for $\left[\mathrm{Mn}_{4.78} \operatorname{In}_{2.22}(\mathrm{ea})_{12}\right]_{\mathrm{n}}\left[\mathrm{In}_{9.79} \mathrm{Mn}_{0.21} \mathrm{Te}_{17}\right]_{\mathrm{n}}$. 